\title{
Scholarly Publishing
}

\author{
MICHAELA. MABE \\ International Association of STM Publishers, Prama House, \\ 267 Banbury Road, Oxford, OX2 7HT, UK. E-mail: mabe@stm-assoc.org
}

\begin{abstract}
Scholarly publishing serves the formal communication needs of scholars or researchers and derives from, and is constructed to reflect, their aspirations and behaviour. Specifically, journal publishing was invented by Oldenburg in 1665 to solve some of the competitive jealousies that existed between the experimentalist founding fathers of the Royal Society. The solutions he came up with have endured to the present day and have even survived the transition to electronic delivery. This article surveys the reasons why this should be so and examines the modern world of electronic journal publishing with particular reference to the players in the publishing cycle, the digital transition, economics and the advent of open access.
\end{abstract}

Scholarly or research publishing serves the formal communication needs of scholars or researchers, but crucially it derives from and is constructed to reflect their aspirations and behaviour. While many aspects of daily life change from year to year or decade to decade, the most fundamental elements of the human psyche do not. Individuals aspire for the esteem of colleagues and want recognition of their unique contribution to any project, whether they are a 21 st century professional or a 17th century experimental philosopher. These psychological drivers are especially strong in academia where an individual's standing depends upon being identified as the originator of an idea or the first discoverer of a phenomenon or result. They can be crudely characterised as ego, vanity, recognition, reward and immortality, and are established for researchers through publication. Because these are human factors, they are unaffected by the medium in which publication occurs and are largely independent of technologically inspired change. In this sense, the fundamental driving principles that govern electronic scholarly publishing are no different from those that govern traditional paper-based publishing. In other ways, however - especially the processes used to create and disseminate data - things are very different. This article attempts to look at both these aspects as well as the challenges of open access. 


\section{The invention of the journal}

The journal is the principal means by which researchers communicate and are evaluated. For almost all empirical studies this is universally true. In most of the arts and humanities (and some of the less quantitative social sciences), however, while the journal is becoming increasingly important, monographic book publication remains the norm. Book publishing is comparatively well understood and continues to be despite the introduction of electronic books. This article will not attempt to survey this dimension: the interested reader is referred to other excellent sources, especially Thompson. ${ }^{1}$ This article will deal almost exclusively with research journal publication.

There are approximately 25,000 active, peer-reviewed learned journals publishing about 1.5 million articles each year. About one million unique authors publish annually for a global audience of roughly 10-15 million readers located in more than 10,000 institutions. ${ }^{2}$ The number of journals and articles continues to grow: each year the number of articles increases by $3 \%$, the number of journals by about $3.5 \%{ }^{3}$ This growth has been relatively consistent over the last couple of hundred years. Its cause is surprisingly simple: the growth in the number of researchers in the world. ${ }^{4}$ In $2007 / 8$ there will be over 1.5 billion downloads of scholarly journal articles at an average cost of one or two euros per download: the electronic revolution has allowed more knowledge to be available to more people than at any previous point in the history of mankind.

Learned publishing by means of the journal first began in January 1665 with Denis de Sallo's Journal des Sçavans. ${ }^{5}$ Henry Oldenburg (1619-77) created the world's first research journal in March 1665 as part of his involvement in the newly founded Royal Society of London (of which he was first Joint Secretary). He did so to solve a number of problems faced by early scientists. Principal among these was the desire to establish precedence: the first authors of a phenomenon or result wanted their priority as discoverer to be publicly acknowledged and secured before they were prepared to share their results with their colleagues. Oldenburg realised that a periodical publication run by an independent third-party could resolve this dilemma for the pioneering scientists of his age by faithfully recording the name of a discoverer, the date he submitted his paper, as well as his description of his discovery. ${ }^{6}$

Philosophical Transactions, the journal Oldenburg set up for 17th century investigators ('the ingenious'), licensed" by the Royal Society (but at his own financial risk and profit ${ }^{8}$ ), did exactly this. In its monthly issues, it registered the name of the authors, and the date that they sent their manuscripts to Oldenburg, as well as recording their discoveries. This simple act secured the priority for first authors and encouraged them to share their results with others, safe in the knowledge that their 'rights' as 'first discoverers' were protected by so doing. 9 
Philosophical Transactions from its outset did not publish all the material it received; the Council of the Royal Society reviewed the contributions sent to Oldenburg before approving a selection of them for publication..$^{10}$ Albeit primitive, this is the first recorded instance of 'peer review'. It was quickly realised by Oldenburg's contemporaries that the accumulating monthly issues of the journal also represented a record of the transactions of science of archival value.

\section{Modern journal practice}

The four functions of Oldenburg's journal: registration, dissemination, peer review and archival record are so fundamental to the way scientists behave and how science is carried out that all subsequent journals, even those published electronically in the 21st century, have conformed to Oldenburg's model. All modern journals carry out the same functions as Oldenburg's and all journal publishers are Oldenburg's heirs. ${ }^{11-13}$

Peer review is probably the most important defining characteristic of the modern learned journal. While many journals explicitly state in their aims and scope that they are 'international, peer reviewed publications', the presence of peer review can be adduced in other ways. Each published paper will generally contain a series of dates (the 'peer review apparatus') indicating the progress of the article through the journal's peer review system. Almost all will record a 'received date', the date the manuscript was received by the journal editorial office, and an 'accepted date', the date the peer review process concluded with the acceptance for publication of the article in the journal. It is also common for journal issues (and increasingly single articles published online) to contain a final publication date as well.

Peer review itself, as commonly practised, involves the systematic, critical review of a submitted paper by two or more scholars from the same academic community as the author. These academic 'peers' are selected by the journal editor and are asked to critique the paper in respect of its originality, methodological soundness, the significance and strength of its conclusions, the degree to which the evidence presented supports the conclusions given, and proper attribution of original sources. While peer review cannot prove that a paper is 'correct' or that the data presented are not fraudulent, it is widely accepted by both authors and readers as greatly improving the quality of reported research. The correctness or otherwise of the conclusions of a paper readily become apparent as further investigations of that field are undertaken. ${ }^{14}$

The published, peer-reviewed journal article performs a unique role in scholarship. It is an on-the-record, validated public statement of the claims made by its authors, not unlike a witness statement made under oath in a court of law. It occupies a central position in terms of the wider set of possible communication 
modes that a researcher may adopt (oral presentations at conferences, early draft versions of a paper, called a preprint, an evaluated review article of other research articles in a field, a scholarly monograph or textbook). It is the evaluated (peer reviewed) public, formal and final nature of the published journal article that makes it so important for its authors, their individual standing and career prospects. Like witnesses each giving evidence under cross-examination in a trial contributing to the jury's verdict, each article forms one of the evidentiary building blocks that eventually allow scientific consensus on any phenomenon to be achieved. The final fixed version of an article published in a journal is therefore part of the 'minutes of science' of that discipline and crucial to its practice.

\section{The publishing cycle}

The movement of information between the different participants in the journal publishing process is called 'the publishing cycle' and often represented as in Figure 1. Here research information, created by an author from a particular research community, passes through the journal editorial office of the author's chosen journal to its journal publisher, and to subscribing institutional libraries often via a subscription agent - before ending up back in the hands of the readers of that research community as a published paper in a journal. This simple graphical representation belies a much more complex reality. First, the cycle is often interpreted as a simple one-to-one connection between an author and a reader rather than the one-to-many connections that in practice occur. Most communities of researchers are international and highly dispersed among research institutions worldwide. Each individual is usually only aware of a small fraction of the total membership of the worldwide community. Secondly, each member of any research community can play one or more of a number of (often simultaneous) roles. For example, all members of the community will be readers but only a smaller number will also be authors. The degree of author-reader overlap will vary according to the

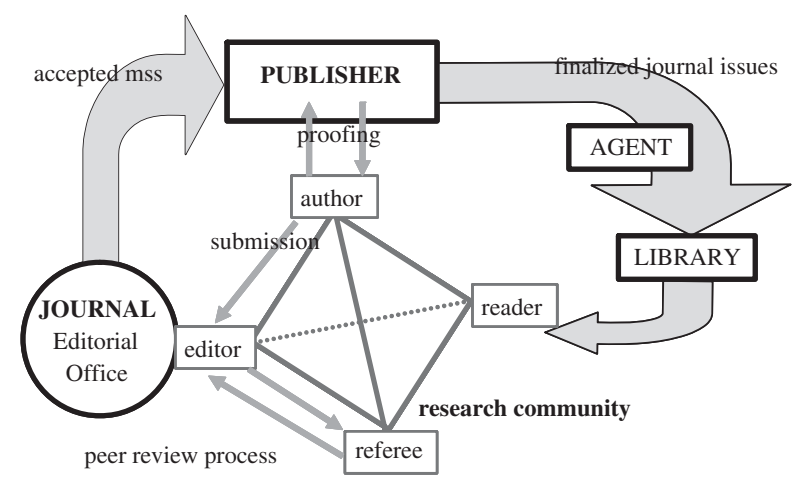

Figure 1. The publishing cycle 
nature of the discipline, small for practitioner communities but almost co-extensive for pure, fundamental subjects. In turn, most authors will at some stage also be asked to act as referees, and a minority of these will be journal editors. In any one year, a journal editor can also act as a reader, an author and even a referee.

\section{Players in the publishing cycle}

The author

About $70 \%$ of authors are working researchers based in universities. The remainder are connected to the research departments of teaching hospitals, government institutions and research-intensive corporations (especially pharmaceutical and chemical companies). Wherever they are located, they have common aims in getting published.

Authors have a very good idea of the quality of their own research work. When considering where to publish a draft paper they will self-assess the level of their work and attempt to match it to an equivalent category of journal. The author selects the journal category in which they would like to have their work published on the basis of a number of factors of which relevance, reputation and ranking in its field predominate. Having identified a 'short-list' of appropriate titles, the actual journal chosen depends upon the direct publishing experience of the author, his or her colleagues or superiors. How did the journal manage the peer review process? How well were illustrations and tables dealt with? How quickly was the last paper published? Were the notes for authors helpful? Based on the answers to these questions, the author will make a final selection. ${ }^{15}$

The motivation for the authors to be seen in a particular journal was described as being primarily to:

reach the eyes of their colleagues, to influence their minds and work, and thus to make an impact on knowledge (not just a contribution to it). ${ }^{16}$

However, this rather selfless description of the motivation to publish overlooks a number of key issues.

Like their forebears of Oldenburg's time, modern authors publish to establish their own personal reputations and their priority and ownership of ideas. The third-party date-stamping mechanism of the journal registers their paper as being received and accepted at a certain date, while the reputation of the journal becomes associated with both the article and, by extension, the author. A journal's reputation ('its brand') is achieved through a host of associations: between the name of the journal and the authors who generally appear there, the quality and originality of the articles published, and the selectivity of the peer review process. As authors publish in more and better journals so they in turn become regarded as the more prolific and better authors. In other words, they associate with known high 
quality brands and this leads to their own names becoming high quality brands in their own right.

For authors, journal publication asserts priority, establishes ownership of an idea, rewards the better authors by giving them recognition and helps build a reputation. In addition, because publications are the only countable and assessable output of research, they have become intimately associated with the evaluation of research programmes, the researchers themselves and the institutions to which they belong. The publication record of a researcher becomes one criterion by which to assess whether they should be the recipient of future research funding; it can also be used to assess eligibility for academic posts and promotions. An additional pressure on the individual author is the use of their published work in the evaluation of their university department with reviews (such as the Research Assessment Exercise ${ }^{17}$ in the UK) affecting the future existence and funding of those departments. Such evaluation is often done on the basis of citations to the articles, the number of published articles and the reputation of the journals. Collectively, this pressure on academics in respect of funding and career progression has come to be known as Publish or Perish. It is sometimes wrongly believed to be the only reason researchers publish, whereas it is really an amplifier of many pre-existing reasons. It sits on top of the fundamental motivating factors that affect all authors whether they are in academia or industry: the desire to see their ideas being publicly credited to them and having a permanent record of their work available in the scientific record.

\section{The journal editor and the editorial board}

The editor of a journal is usually an independent, leading expert in his field (most commonly but not universally a university academic) appointed and financially supported by the publisher. The journal editor is there to receive articles from authors, to judge their relevance to the journal and to refer them to equally expert colleagues for peer review (usually other researchers in the same field as the paper, called referees or reviewers). Peer review, as previously mentioned, is a methodological check on the soundness of the arguments made by the author, the authorities cited in the research and the strength of originality of the conclusions. While it cannot generally determine whether the data presented in the article are correct or not, peer review undoubtedly improves the quality of most papers and is appreciated by authors. Reviewers can recommend acceptance of a paper for publication, its rejection or acceptance subject to specified revisions. The final decision is made by the journal editor on the advice of the reviewers. The review process alone can take from weeks to months, with a similar delay until publication after the article has been accepted, although electronic publishing has greatly reduced delays in this second stage. 
Historically, each journal had a single editor, but the expansion of the size of journals and the increasing specialisation of fields of research mean that it is now much more normal for there to be several editors (usually two or three) each receiving papers and organising refereeing for their area. These editors can be divided between regions of the world (almost all scientific journals are international in scope) or subject specialities or a combination of the two.

The editorial board of the journal usually consists of around 20 or 30 recognised authorities in the field of the publication who are prepared to lend their name and prestige to it. The editorial board members are not remunerated for their position but will receive a free copy of the journal. At the start-up of a new journal, the editorial board will be crucial in obtaining the first papers (which they may write themselves) and encouraging their colleagues to support the new publication. When the title is established, the editorial board is usually asked to assist with policy issues and meets probably no more often than once a year at a key scholarly conference in the field. Such editorial board meetings will be funded by the publisher.

An editor's, and editorial board's, role can be summarised as follows:

to take main policy decisions on which manuscripts to publish so as to provide up-to-date thinking and 'cutting edge' research in a particular field or discipline. There was clearly much personal and professional satisfaction and prestige gained from association with an academic journal, though increased work pressures were seen as eroding benefits. Other areas ... included: how referees were chosen (mainly through personal and professional networks); criteria for assessment of manuscripts (clarity of exposition and writing, originality, and relevance to the field); feedback to authors (a copy of the referees' reports plus a covering letter from the editor); and use of 'blind' refereeing system (removal of authors' name). ${ }^{18}$

\section{The journal publisher}

The role of the publisher is often confused with that of the printer, but it is much wider.

Journals' publishing is not just about producing and marketing a product - it's also about serving a community and about helping develop a focus for a community. The community consists of readers, authors and academic editors who are often the same people - and also involves others who contribute to the information chain, including librarians, subscription agents and other intermediaries. ${ }^{19}$

The journal publisher organises and sustains this link between the journal and the community it serves, by selecting and supporting the right editor, financially underwriting the journal (especially when it is new and has little or no income) and through managing the production, marketing (to both potential subscribers and authors) and distribution, whether in print or electronically. 
Identifying new, niche markets for the launch of new journals, or the expansion (or closure) of existing journals is a key role for the journals publisher. This entrepreneurial aspect seeks both to meet a demand for new journals from within the academic community - and it is noteworthy that journal publishers have been instrumental in the birth of a number of disciplines through their early belief in them and support of new journals for them - and also to generate a satisfactory return on investment. As well as being an entrepreneur, the journals publisher is also required to have the following capabilities: ${ }^{20}$

- Manufacturer - copy editing, typesetting, printing and binding the journals. These services are usually contracted out and the management of the supplier and monitoring of quality levels are the direct task of the publisher.

- Marketeer - attracting the papers (authors) and new subscribers. The attraction of authors - often called 'input marketing' - is principally the function of the publishing or editorial department of a publisher and is achieved through making the journal as attractive as possible to potential submitters of research. This involves ensuring the journal continuously matches both their academic needs in terms of coverage and quality (via continuous creative dialogue with the external academic editor) as well as being 'mechanically' sound in its service dealings with authors and the fulfilment of their needs (efficient acknowledgement of receipt of papers, good standards of proof preparation, quick publication, good disclosure of the contents of the journal through abstracting and indexing services such as Medline, ISI, etc). The other aspects of the marketeer function are those usually to be found in any organisation selling goods and services: promotional literature production and mailing, advertising and exhibitions. In the case of the journal publisher, promotional literature is often produced with two audiences in mind: the 'input market' of potential authors and the 'output market' of readers and potential purchasers.

- Distributor - publishers receive subscription monies in advance of any publication and must maintain a sophisticated subscription fulfilment system which guarantees that goods are delivered on time. They also maintain close working relationships with subscription agents and serials librarians, as well as the academic community.

- Electronic host - electronic journals require many additional skill sets more commonly encountered with database vendors, website developers and computer systems more generally. Such a function is almost entirely new for a publisher and involves the recruitment and retention of highly specialised (and expensive) technical staff. 
In addition to print, sales and distribution and electronic hosting, publishers support the academic work of their journals in a variety of ways, providing guidance to the external, academic journal editor and boards, funding offices, editorial meetings and editorial expenses, together with the investment in the journal's development into new markets or new media, such as the internet. The publisher also has to invest in the 'back-office' systems that keep the journal in business, such as peer review databases, production tracking systems, customer service and subscription systems, warehousing and distribution.

A generally overlooked area of publisher responsibility relates to the underlying wider network of information support: for example standards and technologies that are interoperable, working with the wider information community on integrity and ethical issues, the defence and management of authors' rights. These activities are virtually invisible to the average author or reader but without them the publication systems would be unwieldy and inefficient. A particularly good example of this duty of care is the universal acceptance among journal publishers of interoperability (sadly not seen in other areas of publishing, think of the video and highdefinition DVD format wars), as in the development of the universal linking service CrossRef., which allows seamless navigation between articles. Clicking on a reference automatically takes the browser to the article referenced without any intermediate pages. $^{21}$

\section{Scholarly publisher types}

Scholarly publishers can be classified in a number of ways: according to the types of material they publish or according to their business models. Primary publishing involves the publication of content that has never been published before, and most of this article has concentrated on the issues surrounding the dissemination of such original scholarly material. Secondary publishing also has a long tradition (the first abstracting journal appeared just 49 years after Oldenburg's debut) and has largely become the domain of large electronic abstracting and indexing services, such as Thomson Science's Web of Science or Elsevier's Scopus. Tertiary publishing involves the publication of review articles that survey and evaluate the contribution made to a topic in the primary literature. It is very common for most scholarly publishers to publish both primary and tertiary material.

In terms of business model, scholarly publishers come in three broad flavours: learned societies conducting their own publishing, university presses and private commercial companies. The university presses and learned society publishers are also described as 'not-for-profit'. This label can be misleading, since these publishers will aim to have surpluses after expenditures (as all publishers must), but it really refers to where such surpluses end up. In the case of university presses, any surplus will be donated to the university housing it. In the case of the learned societies it will go to their general income to assist in their educational 
and organisational purposes. In the case of the commercial sector it is called profit, is taxed according to the jurisdiction the publisher falls under, and the remaining monies reinvested in the business and redistributed to investors through dividends.

Overall, there are about 2000 publishers publishing at least one journal. Of these, $95 \%$ publish one or two journals only. The top 100 publishers publish about $67 \%$ of journal articles each year. In terms of publisher numbers, about $54 \%$ are learned societies, 33\% commercial companies and 13\% university presses. In terms of their contribution, $65 \%$ of articles are published by the commercial publishers, $31 \%$ by learned societies and $4 \%$ by university presses. There is no easy source for monograph publication statistics, but the exact inverse of the previous data set is highly probable, with university presses far outstripping all others in their research book output.

\section{The digital transition}

Most of the issues now facing journals publishers, serials librarians and scholars could hardly have been imagined 50 years ago, and are effecting greater changes in the serials world than it has ever seen. University libraries have had to face decreasing support in their institutions in real terms (spending on libraries has fallen from $4 \%$ to $3 \%$ of average UK Higher Education Institutional spending since 1980; similar declines can also be observed in the US) while at the same time the size of the literature has more than doubled (growing annually at $3 \%$ in terms of articles and 3.5\% in terms of journal titles). With the advent of online journals the traditional sales model has also changed - no longer is it a 'one subscription-one printed journal' model, but involves electronic licensing negotiations on site-wide access, state-wide access and even country-wide access to the publisher's entire online collection. ${ }^{22}$ Such consortia deals are taking up increasing amounts of both publishers' and librarians' time, but the benefits to libraries are consistent reliable holdings and price increases being fixed at a certain level for a period of time. For publishers, the advantage in striking such a deal may be stabilising a certain level of sales from a particular organisation. The major beneficiary of these deals has been journal users. More material is available to more users now than at anytime in the history of scholarship and levels of access continue to improve with the digitisation of back lists.

Despite all these gains, the move to digital forms of article creation and delivery has introduced challenges that no one could have anticipated. Versions of articles are proliferating. The final published versions in print are not necessarily the same as those available online. Articles are being made available earlier without page numbers, making traditional citation problematical. What exactly is the definitive version of an article, where can it be found and what counts as the 
official publication date? How can a secure digital archive be created? Who should maintain it? How can it be financed? Should authors be allowed to put versions of their articles on to public websites? If so, which version, and does it matter? None of these thorny issues existed in a pre-digital age, but they are fast becoming real practical obstacles to efficient scholarship rather than philosophical conundrums.

These challenges arise from two main features of digital documents: their infinite reproducibility without control; their infinite changeability without necessary sanction by any authority. In a paper world scholarly publishing was 'digital': a document was published or it was not; if it was, then that version was the fixed official and final one. In an electronic world, scholarly publishing becomes 'analogue': a continuum of versions can exist of varying degrees of 'published' and 'final'. Some scholars have argued that this makes it possible for entirely new approaches to exist: a world where papers evolve rather than being published. Although attractive to many commentators, this possibility overlooks the desire of most scholars to see what was known at a particular time, and that of authors to finish a project with its publication and move on. Digital changeability potentially evokes a nightmare world of digital symposia that never end: a constant stream of argument and counter argument without closure by a session chairman, and an ever-expanding amount to read about every opinion posted. Most investigators do not see this as an enhancement of the current paradigm.

The digital transition has affected (and continues to affect) every party in the publishing cycle: while some processes have become very easy (such as distribution), others have become much more complex. In part this is a natural consequence of the phenomena of infinite reproducibility and changeability noted above. But it is also due to a breakdown of the Aristotelian unities where documents are concerned: for paper documents, the content, the 'browser', and the archive are indivisible; for digital documents, content and browser are separable, the browser implies additional hardware on which to run it, and the archive may or may not be included. ${ }^{23}$

Figure 2 attempts to capture (in dark grey) the main areas of change for both the processes and the actors in the traditional publishing cycle after it has gone through the digital transformation.

\section{The digital transition and the research community}

The advent of electronic submission as the norm and the rapid introduction of electronic peer review management systems mean that researchers have had to change their publishing behaviour whether they are authors, referees or editors. Authors are expected to submit electronic manuscripts via an electronic gateway for the journal of their choice, imposing constraints on the software and formatting they can use. In turn, editors are expected to use electronic peer review and manuscript management systems to select referees from a database, forward the 


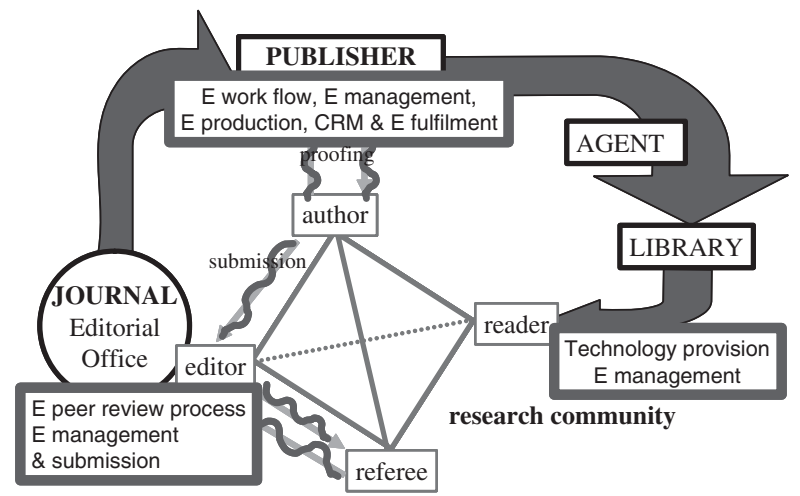

Figure 2. The electronic publishing cycle

manuscript on to them and receive comments back. Referees can expect to receive image files of the manuscript as an e-mail attachment (usually in the Adobe PDF format) which some find tricky to annotate electronically and will often require printing out locally. Whichever of these three roles they occupy, most researchers feel a little mixed about the move from paper to electronic. While the transition has undoubtedly improved the speed of transit of documents, made the preparation of tables, diagrams and photos easier, it has also moved much of the burden for such origination away from typesetters, art workshops and the publishers onto the producers, editors or reviewers of the material.

The introduction of software and systems has inevitably systematised submission and peer review. The processes and forms adopted now depend much more on the configuration and choice of the electronic submission and peer review management systems than on the specific journal and editor. The demand by authors to know more about the status of their manuscripts in peer review and production can only be satisfied if common systems are in use between different journals from the same publisher. Electronic submission requires routines for the logging and transformation of received files, their management and trafficking. Such facilities inevitably have to be centralised per publisher rather than per journal, with many titles sharing the same system. Authors of electronic manuscripts will effectively submit to the publisher rather than the journal or its editors, although this may be disguised with each journal apparently possessing its own submission website. In addition, peer review processes, once solely in the domain of the journal editor, require websites and support from the publisher, who can only deliver article status information if the editor's data is held on the publisher's computer.

All these changes subtly alter the balance that existed between the world of scholarship and the world of commerce, yet instead of simply moving work from one actor to another, they have actually created new tasks that never before existed. Scholars are now charged with greater involvement with the origination 
of material and the publisher less, but the problems of file conversion, management and electronic hosting, not to mention the difficulties of selling virtual rather than actual products, have more than compensated.

\section{The digital transition and the publisher}

Very few of the processes that publishers have traditionally managed are unaffected by the digital transition. To these must be added entirely new activities with implications for staffing and overhead costs: for example, electronic fulfilment systems with complex customer relationship management software, secure archiving and hosting, to name just two. The changes have been so profound that publishing organisations have had almost entirely to re-invent themselves since the early 1990s.

The editorial functioning of each journal, once almost totally the domain of the academic editor, increasingly becomes part of the publishers' systems through the introduction of peer review management, submission and trafficking software. The software has to be designed from scratch or selected and bought-in. In either case it requires support as well as training of editors and staff.

The production process has changed out of all recognition. Electronic files have to be converted from what was received from an author to a common format, their special characters, tables and figures transformed, and the final files output in two modes: one for printing; one for online uploading. The development and management of electronic file flows is a very different process to that of the paper world, requiring new tools and software services, retraining of staff and the hire of those with new competencies.

The supply of web editions of journals requires access to, or the development of, online hosting facilities. In the case of the latter, this involves specialised equipment and staff as well as considerations of data security and permanence, none of which were present in the pre-digital world. The archives involved are not just simple data stores but living, interconnected collections of papers with complex cross-linking both externally and internally. Unlike a paper archive, these require active intervention. All this has economic implications: with paper, the archive was delivered and paid for together with the browser and the content, no further action was required by the publisher; electronically, for the archive to work and remain accurate, the publisher has to maintain links and services. The problem is that customers will legitimately expect perpetual electronic access to the archive of material to which they have subscribed without further cost, and they will expect this even for material they no longer purchase.

\section{The digital transition and the library}

Digital entities are more difficult to manage for both the publisher and the librarian. For libraries, even relatively simple tasks, like checking in journals 
issues to ensure a subscription is being fulfilled properly by the publisher, become much more complex. Instead of a package automatically arriving through the mailbox and needing to be opened and processed, the library has to remember to go online and check that access to each of the issues of each journal it subscribes to has been enabled. The breakdown of the Aristotelian unities for electronic publication - the separation of content, browser and archive - means that although shelving and space are no longer issues for electronic journal collections, the purchase of computer hardware and software and its regular updating certainly are. The increasing popularity of bulk purchasing and consortial arrangements means that the act of purchasing is much more complex. Instead of title-by-title decisions to subscribe to journals, a library is faced with negotiating and implementing licensing agreements for access to a range of titles with differing conditions of access and cost.

\section{The digital transition and publishing economics}

Perhaps some of the greatest challenges that face the digitally-transformed publishing system are perceptual and economic. Many observers of, and participants in, the scholarly communication system seem to equate physicality with cost. That is to say, they believe that the physical processes of printing and distribution have always been the principle cost areas for publishing and that these have been totally eliminated by going digital. Based on this analysis they conclude that ' $e$ equals free' and are surprised when electronic publications are neither substantially cheaper nor free to purchase.

A very simple model of publishing costs can rapidly demonstrate why this is wrong. In essence there are only two types of cost: fixed costs that relate to the creation ('origination') of the first copy of any publication; variable costs that relate to its reproduction and distribution. Editor and editorial office, copy-editing, and typesetting are among the traditional fixed costs of journal publication and these are unchanged by going digital; paper, ink, printing and binding, postage and shipping are the traditional variable costs that potentially disappear for electroniconly publication. For most paper journals the variable costs represent about $10-20 \%$ of the total, although for the high circulation hybrids (journals of broad general interest with a journalistic magazine component like Nature or Science) this can be substantially higher. For electronic journals, although the variable costs are essentially eliminated, the change in technology and work processes (the need for electronic peer review systems, file transfer mechanisms, file workflow management, electronic fulfilment, customer relationship management, electronic hosting, disaster recovery and specialised staff, for example) increase the fixed costs over those that applied with paper. Consequently, any saving in costs of digital publication is largely eaten up by the costs of new activities. Savings potentially range from $0-10 \%$ at the very most. For such economies to apply 
across the board, all journals would have to be produced as electronic-only publications. For the time being, however, most customers still wish to be provided with a paper version as well as an electronic one. To do this requires the maintenance of two production tracks with all the old processes as well as the new ones. Paradoxically the digital transition has resulted in publishers bearing a dual cost structure that is more expensive than the traditional paper world and which is unlikely to disappear until print itself disappears. An excellent overview of the costs of publishing is to be found in Tenopir and King, ${ }^{24}$ with a recent review article by Don King ${ }^{25}$ and a report by the UK Research Information Network ${ }^{26}$ also covering these issues.

One area that continues to bedevil thinking is the notion of peer review costs. Commentators often correctly point out that academic referees conduct peer review as a pro bono activity that they see as part of their wider academic role. As a result of this, they argue, peer review has zero costs. This is a major misconception. When publishers talk about the costs of peer review they actually mean the costs of having an editor and an editorial office that manages the peer review process, not to mention the creation and continued existence of the journal in the first place. These costs are intimately tied up with the issues of branding that are so important to the success of the journal with academic authors and readers. While figures vary tremendously, about one third of all costs of publishing a paper derive from editorial support (including the management of the peer review process, the fees and expenses paid to the editor(s) and editorial office costs and overheads) and brand management by the publisher. Many commentators have calculated average article costs at around $\$ 3000-\$ 4000:{ }^{27}$ about $\$ 1000-\$ 1500$ will be the editorial costs essential to their being any peer reviewed content in the journal at all. These costs vary by size of journal (larger journals will need more editors and editorial offices) and by the rejection rates. For very selective journals, rejection rates of $95 \%$ or greater are not uncommon. This will mean that for every five papers that finally get published 95 will have been peer reviewed (with all the associated editorial costs) and rejected. For these journals, the editorial and peer review costs will be at least 2-3 times greater than the average journal.

\section{Open access}

With the exception of the early debates about what electronic publishing might mean and how this might affect the future of the scholarly journal, there are probably few other topics that have generated as many words both spoken and printed as 'open access'. Even its definition can be highly contentious, depending on where in a spectrum of belief sets one might be regarding issues of copyright and re-use. Space does not permit a treatment of these issues here, but the hardy reader is referred to the extensive writings of $\mathrm{Harnad}^{28}$ and $\mathrm{Suber}^{29}$ for more on this. 
In this article, however, we will use a rough working definition of open access as a combination of philosophy and business models allowing all readers (not just those within institutions) free access to scholarly research literature without payment at point of use.

Open access comes in a number of variants dependent upon what is made open, when it is made open, and how it is made open. The what question is itself a derivative of the progressive smearing out of the published/unpublished dichotomy we noted above. Three what stages may be distinguished:

- stage one - author's un-refereed draft manuscript for consideration by a journal, often called (especially in physics) a preprint

- stage two - author's final refereed manuscript accepted for publication by a journal and containing all changes required as a result of peer review

- stage three - final published citable article available from the journal's website

In terms of when, we can observe two possibilities: immediately upon publication or at some time period after it, often called an embargo period. The how question is largely one of business model, if there is one.

Using these definitions it is possible to disentangle the often complex mix of open access variants currently practiced.

1. Full open access: stage three; immediate; flipped business modeloften called 'The Gold Route'

In this version of open access the final published paper is made fully accessible to all on the internet immediately upon publication by a flipped business model whereby publication is paid for rather than access. This approach has many positive virtues. It reconnects the cost of the literature with the volume of output, it provides universal access to scholarly content and it provides a business model for publishers. There are not-insignificant obstacles to be overcome, however, before its wider adoption.

Flipping the model creates new structural and political issues over who pays and by how much. As noted above, publication charges will vary by journal, with highly selective titles (e.g. those rejecting 95\% of submissions) costing 2-3 times as much as the average. Where research grants exist, payment for publication could be made through them, but only $60 \%$ of all authors are grant supported and $25 \%$ come from poor institutions in developing nations. Research intensive universities could end up paying the lion's share while others (such as research corporations who currently fund $20 \%$ of subscription sales) pay nothing at all. Placing even more control over who is funded to publish (and where) puts great pressures on academic freedom. 
2. Delayed full open access: stage three; delayed; existing business model

Here, publishers choose to make the final published articles of selected titles fully open at some time period after publication. The journals have been carefully chosen from disciplines or business model types where free availability after an embargo period will not compromise sales. Highly newsworthy journals or those in very rapidly developing subjects constitute most of the examples of this type of open access. While this approach is complementary to traditional publication approaches and business models it is inevitably patchy: few journals (an estimated $0.1 \%$ of the total) or subjects could survive below six month embargo periods.

\section{Self archiving open access: stage two; immediate/delayed; no business model - The 'Green' Route}

An outgrowth of the institutional repository movement, this approach to open access depends upon a number of assumptions. First, that stage two is good enough for scholars; second, that authors, their institutions and publishers will collaborate over making stage two content available on public websites; third, that creating a free simulacrum of the paid for literature will not undermine its future saleability.

For many researchers, stage two may just be good enough (although there are clearly liability issues for medical articles and the like where drug dosages and units of measurement have not been through rigorous copy editing). The second assumption is open to greater challenge: authors have not yet demonstrated great confidence or commitment to self archiving even though most publishers have allowed it when it takes place in a non-systematic way. In fact getting content into repositories seems to require the 'big stick' of an institutional or funder mandate, otherwise compliance levels barely reach $5 \%$. The biggest concerns of the publishing community lie with the combination of the 'big stick' with the third assumption, the idea that with systematically deposited stage two materials accessible after six or 12 month embargo periods, journals would remain economically viable. There are mixed research results on this matter. It is claimed that the coexistence of the ArXiv physics repository with physics journals demonstrates that this concern is unjustified. ArXiv, however, remains largely a stage one repository where no conflict would be observed, although it does contain some stage two (and occasionally stage three) content, which so far at least has caused no journal cancellations. However, what has been observed by physics publishers is a significant migration of use from the 'official' journal articles to those versions stored on ArXiv. As downloads decline from the purchased access to the physics journal literature, it would be a brave librarian who continued to pay for the official titles when their scholars were actually using the free version. 


\section{Conclusions and future prospects}

Space has not allowed for more than the most superficial survey of the current publishing scene. Most observers would be struck, I believe, by the surprising stability and continuity of the journal system. Although the nature and delivery of electronic serials would astonish Henry Oldenburg and his friends at the Royal Society, they would also recognise that the essential functions of the scholarly journal remain unchanged. They would remark on the range of communication tools available to the modern researcher, from mobile phones to personal digital assistants allowing for roving e-mail access. But I think they would also conclude that these are all tools, all means to an end. Verbal discussion, written exchange, formal publication - all three of these modes existed for Oldenburg and they certainly exist for researchers today: technology has just extended their reach and utility. Telephony increases the range and potential for person to person discussion; e-mail speeds up the traditional form of the letter; the world wide web allows immediate distribution of the written word and data. There are new tools but they are all used to make more efficient the same old purposes.

Perhaps the most enduring effect of the digital transition has been to formalise the informal. The boundaries between conversation, correspondence and formal presentation are being blurred. Once ephemeral chats between scientists now occur by e-mail, leaving a permanent written record on computer servers, and this changes the status of the interaction: nothing is ever 'off the record'. Even online journals that allow articles to be commented on by readers (such as the British Medical Journal) are not an entirely new thing, they are merely a more formal written analogy to one of academia's most cherished institutions: the formal seminar with questions and answers.

The growth of social software and tools such as blogs and wikis is having yet further effects in this direction. Wikis (collaborative software that allows multiple authors to collectively write web pages) lend themselves to certain areas of research rather well, for example the phenomenon of working papers in economics where scholars collectively write a work. The use of internet chat relay software allows real time collaboration and discussion around the world, and the creation of virtual workshops and conferences where all interaction gets written down. If the social status of these tools is examined it becomes clear that each is carving out a role in helping humans interact: we are not seeing entirely new ways of communicating, just more effective ways.

The open access movement has led to changes in the traditional ways journals have been financed and has opened up novel approaches to providing society at large with access to the scholarly literature. Which of the various approaches to open access will predominate and how this may or may not interact with the complex ecosystem that is formal publication remains to be seen. It is at least 
clear that some journals (and perhaps other communication vehicles) will adopt this approach. How sustainable this might be in the long-term and how much of a mixed open and paid access economy there will be is unclear.

Will the current ferment ever affect the fundamentals of scholarly publishing? It is impossible to tell, but based on the fit between journal functions and the human needs of researchers, journals and their like are probably around for some time to come.

\section{References and Notes}

1. J. B. Thompson (2005) Books in the Digital Age (Polity).

2. M. A. Mabe and M. Amin (2002) Dr Jekyll and Dr Hyde: author-reader asymmetries in scholarly publishing. Aslib Proceedings, 54(3), 149-157.

3. M. A. Mabe (2003) The growth and number of journals. Serials, 16(2), 191-197.

4. M. Mabe and M. Amin (2001) Growth dynamics of scholarly and scientific journals. Scientometrics, 51(1), 147-162.

5. A. J. Meadows (ed.) (1980) Scientific Publishing in Europe (Amsterdam: Elsevier).

6. A. R. Hall and M. B. Hall (1965-86) Correspondence of Henry Oldenburg (Madison: University of Wisconsin Press). Letters from Oldenburg to Boyle 24 November 1664 and 3 December 1664.

7. At this period in England, publishers required a licence to publish from the Crown. The Royal Society held such a licence, which Oldenburg used. This was the Royal Society's sole involvement in the project. Philosophical Transactions only became the official journal of the Society in 1752 when it took over full responsibility for the publication, including its finances.

8. M. B. Hall (2002) Henry Oldenburg (Oxford: Oxford University Press), p. 86 [Philosophical Transactions, No. 12, 7 May 1666].

9. A. R. Hall and M. B. Hall (1965-86) Correspondence of Henry Oldenburg (Madison: University of Wisconsin Press). Letters from Boyle to Oldenburg 27 August 1665 and Oldenburg to Boyle 29 August 1665.

10. Royal Society of London, Order in Council, 5 March 1665.

11. J. M. Ziman (1968) Public Knowledge (Cambridge: Cambridge University Press).

12. J. R. Ravetz (1973) Scientific Knowledge (Harmondsworth: Penguin).

13. R. K. Merton (1973) Sociology of Science (Chicago: University of Chicago Press).

14. A. Mulligan (2004) Is peer review in crisis? Perspectives in Publishing, No. 2, available at http://www.elsevier.com/framework_editors/pdfs/ PerspPubl2.pdf; and the publications of Sense About Science available at http://www.senseaboutscience.org.uk

15. See presentation at Fifth Fiesole Retreat, Oxford 2003: M. A. Mabe 'What do authors really care about?' available at http://digital.casalini.it/retreat/ 2003_docs/Mabe.ppt 
16. Stefan Harnad in debate at British Computer Society Electronic Publishing Specialist Group 8 June 1995, reported in Anon. (1995) The present generation of publishers is doomed. Learned Publishing, 8(4), 249.

17. Research Assessment Exercise: http://www.rae.ac.uk/

18. P. Sowden and P. Smart (2000) Careers in Journals Publishing, ALPSP, http://www.alpsp.org/ngen_public/article.asp?id=200\&did=47\&aid $=$ 355\&st=\&oaid=-1; see also R. Campbell, G. Page and A. Meadows (1997) Journal Publishing (Cambridge: Cambridge University Press).

19. D. P. Carrigan (1996) Journal of Scholarly Publishing, 27(4), 214.

20. A useful overview of the various departments and roles within a publishing company can be found at the Publishers Association UK website: http://www.publishers.org.uk

21. See http://www.crossref.org/01 company/02history.html

22. T. J. Sanville (2001) A method out of the madness: OhioLINK's collaborative response to the serials crisis. Serials, 14(2), 163-177.

23. M. A. Mabe (2001) Digital dilemmas: electronic challenges for the scientific journal publisher. Aslib Proceedings, 53(3), 85-92.

24. C. Tenopir and D. W. King (2000) Towards Electronic Journals (Special Library Association).

25. D. W. King (2007) The cost of journal publishing. Learned Publishing, 20, 85-106.

26. Research Information Network Report (May 2008) Activities, Costs and Funding Flows in the Scholarly Communications System in the UK, available at http:/www.rin.ac.uk/costs-funding-flows

27. A. Odlyzko (1997) The economics of electronic journals. First Monday, 2. http://www.firstmonday.org/issues/issue2_8/odlyzko/index.html; Tenopir and King (2000) Towards Electronic Journals (Special Library Association).

28. S. Harnad (1990-) E prints on Open Access. Available at http://users.ecs. soton.ac.uk/harnad/intpub.html

29. P. Suber (2007) Open Access overview. Available at http://www.earlham. edu/ peters/fos/overview.htm

\section{About the Author}

Michael Mabe is Chief Executive Officer of the International Association of Scientific, Technical and Medical Publishers, for 40 years the global voice of research publishers large or small, commercial or not-for-profit. He has nearly 30 years' experience in various publishing, research and communications management roles for OUP, the British Standards Institution, Pergamon and Elsevier. He is a Visiting Professor in Information Science at University College London, and an Adjunct Faculty Member of the College of Communication at the University of Tennessee, Knoxville, USA. 